\title{
The impact of genetics and genomics on public health
}

\author{
Angela Brand ${ }^{*, 1}$, Helmut Brand ${ }^{2}$ and Tobias Schulte in den Bäumen ${ }^{1}$ \\ ${ }^{1}$ German Center for Public Health Genomics (DZPHG), University of Applied Sciences, Bielefeld, Germany; ${ }^{2}$ Institute of \\ Public Health Northrhine-Westphalia (lögd), Bielefeld, Germany
}

Public health practice has to date concerned itself with environmental or social determinants of health and disease and has paid scant attention to genomic variations within the population. The advances brought about by genomics are changing these perceptions. In the long run, this knowledge will enable health promotion messages and disease prevention programmes to be specifically directed at susceptible individuals and families, or at subgroups of the population, based on their genomic risk profile. As the controversial discourse in science and health politics shows, the integration of genomics into public health research, policy and practice is one of the major challenges that our health-care system is currently facing. European Journal of Human Genetics (2008) 16, 5-13; doi:10.1038/sj.ejhg.5201942; published online 24 October 2007

Keywords: public health genomics; genetics, genomics and population health; prevention; health policy; inequalities in health and social exclusion; public health ethics

\section{Introduction}

Medicine is currently undergoing extraordinary developments from its morphological and phenotype orientation to a molecular and genotype orientation, ${ }^{1}$ promoting the importance of prognosis and prediction. ${ }^{2-6}$ The advances in modern biomedicine need to be transferred and translated to public health as the new understanding of the causation of diseases and their pathways enable healthcare systems to modify their prevention strategies. The vision for public health is not new as the integration of genomics has been added to the agenda many years ago:

'... It is clear, that the science of genomics holds tremendous potential for improving health globally.... The specific challenge is how to harness this knowledge and have it contribute to health equity,

*Correspondence: Professor A Brand, German Center for Public Health Genomics (DZPHG), University of Applied Sciences, Kurt-SchumacherStrasse 6, D-33615 Bielefeld, Germany.

Tel: + 49521106 7864; Fax: + 49521106 7898;

E-mail: angela.brand@fh-bielefeld.de

Received 2 June 2005; revised 20 September 2007; accepted 25 September 2007; published online 24 October 2007 especially among developing nations...'. This is a quote by Gro Harlem Brundtland, former Director General of WHO, which can be found in the year 2000 'Report of the Advisory Committee on Health Research'.

At the same time, Craig Venter, former president of Celera Genomics, stressed the significance of this issue at the occasion of a symposium about the future of public health at the Harvard School of Public Health:

'Three years ago the human genome - the 'book of life' - was largely unknown. Today, anyone can read what it contains. Genomics is already providing fascinating insights into our species' evolution and clues to the some of the differences between individuals in susceptibility of diseases. The key question for public health, however, is whether it will improve the health of all of the world's people, or whether it will just widen the technology gap between rich and poor. Ask people what they understand of the potential of genomics for human health, and many will talk about an unprecedented opportunity to develop new drugs and vaccines. Others are 
concerned that the poor will gain nothing, while the rich will gain a kind of 'boutique medicine': the opportunity to buy a full analysis of their personal genetic makeup, and then purchase designer therapies. If genomics is to make a major impact on global health, it will have to help provide affordable population-wide tools for combating common diseases....

\section{The International and European dimension of Public Health Genomics}

These conceptual outlines have stimulated both the Rockefeller Foundation and the European Commission to support groups that address these issues as they saw a need to shape a framework for new public health actions. The Rockefeller Foundation initiated the Bellagio Group on Public Health Genomics in 2004, which was led by Wiley Burke (Seattle), Muin Khoury (CDC, Atlanta) and Ron Zimmern (PHG Foundation, Cambridge), and developed a first description of the enterprise of Public Health Genomics (Figure 1).

The meeting was attended by a multidisciplinary group of 18 experts from Canada, France, Germany, the United Kingdom and the United States. The key outcome ('Bellagio Statement') was that the participants unanimously agreed first on the vision for and the scope of the enterprise covered by the field referred to as public health genomics and second to establish an international forum for its promotion, to be known as the Genome-based Research and Population Health International Network or GRAPH Int. The use of the term Int signifies that the collaboration is not only international but also interdisciplinary and integrated.

The objectives of GRAPH Int are to provide an international forum for dialogue and collaboration, to promote relevant research, to support the development of an integrated knowledge base, to promote education and training, to encourage communication and engagement with the public and other stakeholders and to inform public policy. The vision and the ultimate goal of both the enterprise and the network is the effective translation of genome-based knowledge for the benefit of population health.

Genetic determinants play an eminent role in the current European Union health strategy. To create sound genomics policies and programmes, public health should get involved and, moreover, take the lead by applying the three core functions of public health (assessment, policy development, assurance) to the provision of genetic health-care services.

The European Commission has, in its report on 'Life Sciences and Biotechnology' (COM(2004) 250, 7 April 2004), committed itself to gaining high quality in genetic testing and increasing 'cooperation and exchange of information to enhance coherence and disseminate best practice'. Furthermore, in work plan 2005 of the

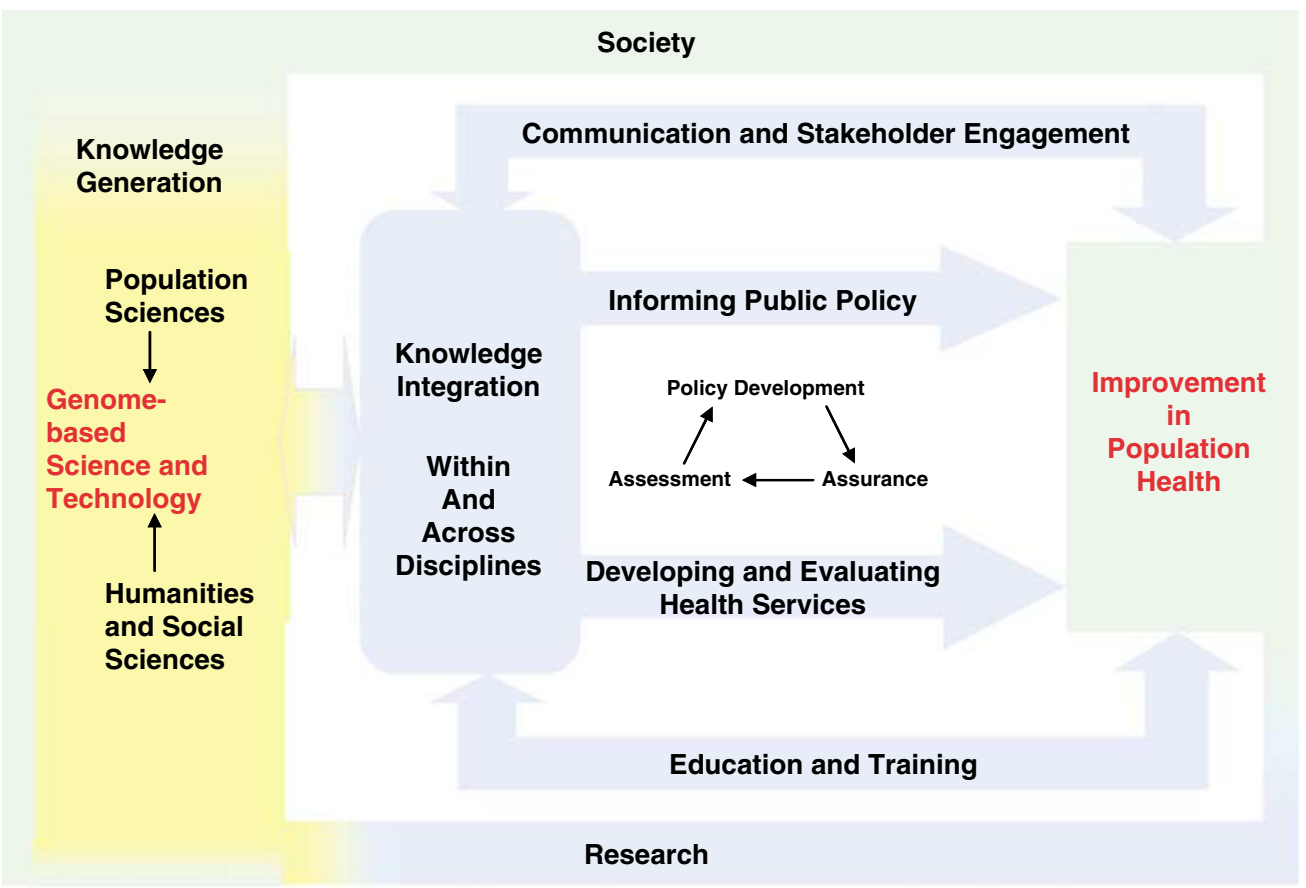

Figure 1 The Public Health Genomics (PHG) enterprise (Bellagio Model). The figure displays the core tasks of PHG between the 'knowledge generation' and the overall goal 'improvement in population health'. (Source: Bellagio Statement. Genome-based Research and Population Health. Report of an expert workshop held at the Rockefeller Foundation Study and Conference Center, Bellagio, Italy, 14-20 April 2005). 
'community action in the field of public health,' the European Commission calls for an application for a 'networking exercise ... to lead to an inventory report on genetic determinants relevant to public health...'

Thus, a European network on public health genomics has been initiated: (1) to develop links with relevant community programmes and actions and with national and regional initiatives to promote synergy and avoid overlaps; (2) to gather and exchange information concerning best practice to assess and prepare the development of community policies, strategies and measures; (3) to contribute to a high level of health protection and improvement of public health; (4) to take into account the need for supporting Member States' actions and enhanced cooperation in the European Union context, legal obligations and their implementation; and (5) to create self-sustainable mechanisms ${ }^{7}$ that enable the Member States to coordinate their health-related activities in the field of public health genetics.

In 2005, the General Directorate for Health and Consumer Protection of the European Commission (DG SANCO) decided to fund the Public Health Genomics European Network (PHGEN), which is administrated by the Landesinstitut für den Öffentlichen Gesundheitsdienst NRW Bielefeld, Germany, the German Center for Public Health Genomics in Bielefeld, Germany, and the Public Health Genomics Foundation in Cambridge, UK. The group advises the EC on health policies and on the integration of genome-based knowledge within the 'health in all policies' doctrine.

\section{Viewpoints}

There are, of course, compelling reasons to think globally in terms of global health or on a European level when we face the challenges deriving from genomics. ${ }^{8,9}$ Still, public health is used to act locally, and PHGEN has reacted on this need by establishing National Task Forces on Public Health Genomics in most EC Member States and some EFTA/EEA countries. The National Task Forces are predestined to bear the local regulatory and ethical framework in mind.

The key question for all these new institutions is whether currently 'the right things' are being done on a European, national or local level. Are public health strategies evidence-based? Thus, the European public health agenda demands a vision that reaches beyond the research horizon to arrive at application and public health impact. ${ }^{10,11}$ What is the future role of genomics in this scenario?

In February 2004, the first international symposium on public health genetics entitled 'Public Health Genetics Experiences and Challenges' was hosted at the Center for Interdisciplinary Research (ZiF) in Bielefeld, Germany, internationally well known as a 'think tank' in science. ${ }^{12}$ At this symposium, contrasting viewpoints about the relevance of genomics for public health were presented:
In the opinion of Neil Holtzman, Professor emeritus of Genetics and Public Policy Studies at the Johns Hopkins Bloomberg School of Public Health, '...there is little need for further integration of genetic services and education into public health especially in countries in which public and private health services are dichotomised...'. Almost in contrast to this opinion, Ron Zimmern, Director of the Public Health Genomics Foundation in Cambridge, stresses that although public health genomics is still in its infancy, '... rapidly advancing science and patient and public expectations require a strategic approach to the assessment, development and implementation of genetic services using all the skills of the public health practitioner. The development of policy for these services must start now, given the pace of genetic science, particularly in view of need to educate and train a whole cohort of practitioners in the principles of genetics and molecular science. The focus on prevention ... should seek to use to its best advantage the opportunity embraced by a better understanding of the gene, while holding back those demands of both patients and physicians where evidence is insufficient to justify significant investment. The grasp of both medical and management perspectives available to the public health physician imposes a special responsibility to take up and develop this aspect of public health practice.'

Many conferences on genomics and its impact on public health have taken place in the meantime, but still we see the same range of opinions from scepticism to euphoric expectations that we have seen at the Bielefeld meeting. Still, it needs to be acknowledged that the conferences and the statements have not yet changed the concepts of public health in Europe.

The emerging genome-based knowledge demands a conceptual shift in both public health and medicine, as many public health practitioners can see a clear need to adjust concepts of prevention and health service delivery in their every day work life. As a consequence, we can describe a dichotomy: genomics needs to understand how it can include public health aspects in its work programme while public health needs to analyse how genomics changes the concepts of public health. The second approach is seen as the core task of Public Health Genomics. Still, there is an interdependency between the two directions; for example, as Public Health Genomics is also concerned about the organisation of genetic services and the genetic health literacy of the population. ${ }^{13}$

How can one deal with these diverging opinions? ${ }^{14,15}$ Where is the truth? Or maybe we should rather ask, is there any truth? What is the challenge for public health?

\section{The challenge for public health}

Multidisciplinary European and US public health institutions and platforms such as the Public Health Genomics 
Foundation in Cambridge (PHG Foundation), UK, the German Center for Public Health Genomics in Bielefeld (DZPHG), or the US National Office of Public Health Genomics at the Centers for Disease Control and Prevention in Atlanta (CDC), who work closely together with researchers from genetic and molecular science ('modern and systems biology') as well as from population science, humanities and social science, are much more optimistic about the relevance of genomics for public health than most geneticists. $^{12,16-18}$ They all have strong links or are even part of the respective national genome research projects in these countries and are translating genomic knowledge from biotechnology through (genetic) epidemiology into public health ('translational research'). By using methods like horizon scanning, fact finding and monitoring to identify research trends as early as possible, they are already doing a prospective evidence-based evaluation, that is, an evaluation that is already carried out in the process of basic research and not just in the (retrospective) process of the implementation of public health strategies and policies, ${ }^{19}$ which always will tend to lag behind.

In the past 20 years, the advances in genome research have revolutionised knowledge of the role of inheritance in health and disease. ${ }^{20}$ Nowadays, it is known that DNA and RNA determine not only the cause of single-gene disorders, which affect millions of people worldwide, but also predispositions ('susceptibilities'), ${ }^{21}$ which are based on genotype and haplotype variants, ${ }^{22,23}$ to common diseases. The new technologies will allow researchers to examine genetic mutations at the functional genomic unit level ${ }^{24}$ and to better understand systems biology, epigenomics, pleiotropic effects, the significance of environmental factors such as chemical agents, nutrition or personal behaviour $^{25}$ in relation to the causation of diseases like cardiovascular diseases, ${ }^{26}$ allergies, cancer, psychiatric disorders or infectious diseases. ${ }^{27,28}$

The advances in public health do not correspond yet to the emerging knowledge we have seen in genomics in the past decade. The Wellcome Trust Case Control Consortium has recently published the preliminary results of a genomewide association study, which highlight the manifold public health challenges deriving from genetic research. ${ }^{29}$ Common complex disorders require the integration of genome-based and secondary data in both the medical and public health settings. On a conceptual level, public health and medicine seem to converge as the assessment and stratification of risks, which becomes essential for the individual and society at large. The level of genomic knowledge in certain fields such as diabetes ${ }^{30}$ requires an urgent shift of prevention, but public health practitioners seem to be reluctant to draw conclusions from the existing evidence. In the field of infectious diseases, the situation is slightly different as pandemics have alerted all stakeholders that genome-based knowledge needs to be used to prevent future incidents. ${ }^{31}$
Evidently, these rapid advances in genomics and accompanying technologies are triggering a shift in the comprehension of health and disease as well as in the understanding of new approaches to prevention and therapy. ${ }^{32-34}$ The emerging knowledge also opens a window of opportunity for other sciences such as law or ethics to develop a normative framework before genomics becomes a mass application. ${ }^{35}$ What conclusions can be drawn from this knowledge and how can it be translated into policies ${ }^{19}$ and practice in a responsible and timely manner?

Clarifying the general conditions under which genomic knowledge can be put to best practice in the field of public health, paying particular consideration to the ethical, legal and social implications ${ }^{12,17,35}$ is currently the most pressing task in Public Health Genomics. Aiming the application of genetic and molecular science to the promotion of health and disease prevention through the organised efforts of society, integral to its activities is a dialogue with all stakeholders in society, including industry, governments, health professionals and the general public. ${ }^{18}$ Thus, the integration of genomics into public health research, policy and practice is one of the major future challenges for our health-care systems. ${ }^{36,37}$ Expertise is already feasible and can be clustered and evaluated for a socially accountable use.

For example, in a condition like coronary heart disease, to be a heterozygote for the LDL receptor gene confers an increased risk for developing this condition. But, as it is also true for all other risk factors (eg, social factors, diet, smoking, physical activity), which have been identified by epidemiologists in this context in the past decades, the presence of the genetic marker is not predictive and those with it may not develop the disease, while those without it may end up with the disease. ${ }^{28}$ Obviously, the scenario is very much like that of coronary heart disease in the presence of raised blood pressure or cholesterol levels: the increased risk implies 'only' a (high or low) probability and the genetic marker is 'just' another modifier in the causality of the disease, and therefore it is neither deterministic nor exceptional. ${ }^{12,13,38,39}$ Nevertheless, the ethical and legal question is how we will handle these susceptibilities. To answer this question, as a first step, population-based large-scale epidemiologic studies would be helpful to measure associations between specific gene variants and environmental factors and the risk of coronary heart disease. ${ }^{40,41}$ Such studies have already been conducted, for example, within the US National Health and Nutrition Examination Survey or within the National Genome Research Network (NGFN) in Germany. ${ }^{42}$ For translating such discoveries into interventions, it is necessary to quantify not only the impact of gene variations on the risk of the condition but also the effect of modifiable factors that interact with gene variations. ${ }^{43}$ On the basis of the knowledge of these attributable risks, 
sound policies and effective interventions can be made. $^{12,40}$

Regarding infectious diseases, research is being expanded to include host genetic factors that influence the susceptibility to certain infectious diseases or even the severity of the condition and that affect responsiveness to vaccines and therapies. The identification of several gene-disease associations for parasitic (eg, malaria), viral (eg, HIV or hepatitis) and bacterial (eg, tuberculosis or cholera) infections provides critical clues to control these infectious diseases. By this, public health strategies will be more effective and efficient.

Policymakers must be aware of the opportunity to improve consumer protection, to monitor the implications of genomics for health, social and environmental policy goals and to assure that genomic advances will be tailored not only to treat medical conditions, but also to prevent disease and improve health. ${ }^{37}$ Sound and well-reflected genetics policies and programmes require a timely and coordinated process for evidence-based policy making that rely on scientific research and ongoing community consultation. ${ }^{44}$ An acceptable and consistent balance between providing strong protection of individuals' interests ${ }^{45,46}$ and enabling society to benefit from the genomic advancements at the same time must be found. ${ }^{12,34,47,48}$ Public Health Genomics can serve as an institutional umbrella for these processes, which are necessary to adopt the 'product' innovations in genomics.

Emerging knowledge from basic sciences requires new translation research, leading to new applied health technologies such as genetic tests (not necessarily DNA-based). Here, identifying needs of genetic tests, ${ }^{47,49}$ weighting benefits and risks (eg, by using the, in most European countries, already well-established public health method of Health Technology Assessment ) of predictive genetic tests and genetic screening interventions, ${ }^{33,50-53}$ assessing the benefits of preventive strategies as well as analysing complex new problems such as 'genetic inequality'38 is essential. In contrast, even if, in terms of genetic susceptibilities and polymorphisms, it will turn out that 'we are all at risk for something', there is potential for social inequalities in health as well as for social exclusion: if genetic tests will not be covered by sickness funds, access to genomic knowledge and thus to individualised and stratified prevention, diagnostics and therapy will lead to a two-tier system. In contrast, even if genetic tests will be reimbursed in most health-care systems, there will be another ethical and social problem, which may be much more discriminating: since genomics is triggering the complexity of knowledge, public health professionals and medical staff will have the task to empower and enable people not only to understand this novel knowledge, but also to make people capable for sound decision-making regarding the application of genetic tests ${ }^{54}$ and therefore to assure a fair equality of opportunities. Otherwise, the gap, between people being able to handle this complexity and those being not, will have the potential of a new kind of social inequality. ${ }^{55}$

In the long run, this supports a conception of public health taking leadership by implementing an evidencebased mode of policy making. This is the reason why in the United States, in the United Kingdom and in Germany, policy makers are following the international Bellagio definition of Public Health Genomics as 'the responsible and effective translation of genome-based knowledge and technologies into public policy and health services for the benefit of population health' (Bellagio Statement 2005).

For the public health community, it is important to stress that Public Health Genomics has nothing to do with gene enhancement or modification and that 'genetic determinism' as well as 'genetic exceptionalism' are obsolete. ${ }^{37}$ Public health strives for a better understanding of genetic factors influencing common diseases, as public health needs this knowledge to reduce or change secondary health determinants such as toxics, false nutrition or behaviour. In addition, it has to be clarified that Public Health Genomics is not synonymous with genetic epidemiology in the same way as public health is not synonymous with epidemiology, and also community genetics $^{54,55}$ is not synonymous with public health genetics, as community health is not synonymous with public health. ${ }^{56-58}$ Still, in the very long run, we are optimistic that the Genomics in Public Health Genomics and the genetic in genetic epidemiology will become obsolete as there will be no public health without genomics and no epidemiology that ignores the impact of genetic determinants.

\section{Public health tasks and responsibilities}

During the past century, achievements in public health led to enormous improvements and benefits in the health and life expectancy of people around the world. Immunisation programmes and better sanitation practices resulted in the eradication or reduction of many infectious diseases as well as in safer food and water supplies. Advances in occupational safety considerably decreased the number of workrelated injuries, illnesses and deaths. In the past 30 years, identification of behavioural risk factors, such as smoking, inactivity and poor dietary habits, gave rise to educational interventions and a decline in death rates from certain chronic diseases.

For the future achievements in public health, the CDC National Office for Public Health Genomics 'Perhaps because of these accomplishments, the determinants of disease and disability - whether natural or human made are often perceived as originating outside the body. Although it has long been recognised that disease generally results from a constellation of host- and environmentspecific factors, scientific and technologic limits have 
concentrated attention on the environment. Exogenous influences will continue to be vital for public health, but focusing solely on these influences may lead to diminishing rates of return compared to the triumphs of the past.

To continue making significant strides, the effectiveness of public health interventions must be strengthened by more fully incorporating knowledge of internal, host-specific factors and their interactions with environmental exposures including the social environment and lifestyles...'

In the realm of social policy making, there is a need to come up with a clear interdisciplinary strategy for assessing and translating this novel knowledge and application right in time. Policy makers now have the opportunity to take action. Precondition for immediate action is strategic planning across health programs, promoting genomics competencies among health professionals, enhancing surveillance and epidemiologic capacity to support evidence-based policy making, building partnerships and seeking input from stakeholders and overcoming systematic barriers between the fields of medicine, genetics and public health. Here, integrating information on genomics into health communication will be an essential tool to generate distributed knowledge.

The likely benefits as well as potential risks of integration of genomics into public health interventions (assessment) should be identified. The framework (corridors) for effective, efficient and socially acceptable policies (policy development) should be described. Steps and ways should be proposed to assure these policies in public health practice (assurance). At the same time, these three steps ('public health trias') describe the core functions of public health agencies at all levels of government. ${ }^{59}$

\section{The need for a coherent and consistent evidence-based policy}

One specific task is to systematically analyse and evaluate every condition of public health interest, such as preventive interventions, by considering genomic knowledge. There is the potential for much more target-oriented and stratified prevention strategies ${ }^{60}$ finally replacing 'a one size fits all' approach. Moreover, clearly there is potential to avoid ineffective, inefficient or even 'faulty' preventive strategies. For example, there is already the potential to differentiate between persons who will respond to certain vaccinations and those who will not. Why then should non-responders take the risk of side effects from vaccination if the vaccination will be ineffective and also have no benefit in this case at all? In this specific situation, which is estimated to be true for at least $10 \%$ of the population, would not primary prevention be immoral? As another example, obesity is influenced not only by lifestyle habits such as inactivity or nutrition but also (in more than $60 \%$ !) by several genetic factors. At least $2 \%$ of these $60 \%$ are only due to mutations in the MC4R gene. Individuals carrying the MC4R mutation are almost 'resistant' to any diet and physical activity. Is it not a 'faulty' preventive strategy giving advice to these individuals that 'five a day' or 'a lowfat diet' will be effective? Would it not be a 'better' (preventive) strategy to give support by respecting them as they are? Of course, there are much more polymorphisms triggering obesity, and there are several polymorphisms that play an important role in the effectiveness of diet and sports. There are even polymorphisms that increase the risk of dying after physical activity. It should be kept in mind that one should be careful about the message 'prevention and health promotion is good for everybody', for example, in terms of a specific diet or physical activity.

In this context, the fundamental rights of the individual, often associated with the 'right not to know' and the 'right to know' in this context, deserve unbiased attention and must be mutually assured. ${ }^{12,61}$ This has so far not been considered in most of the European discussions about the regulation of genetic tests. Besides the questions of reimbursement and access to genetic tests, restrictions in the provision of genetic tests such as physician's proviso, which has already been considered in some countries like Germany, seem to be sheer naive in the era of e-health, globalisation and integrated health services. Instead of proclaiming (ineffective) restrictions, would it not be much more effective and efficient to promote health literacy and to ensure the highest technical quality of products to protect the consumer? ${ }^{61}$ And, from an ethical point of view, would it not perhaps be more appropriate to use the model of 'informed contract', ${ }^{62}$ which is based on the idea of joint duties and rights between the consumer/patient and the provider, instead of continuing to use the model of 'informed consent' and 'informed choice' in the doctorpatient relationship?

New genetic technologies will force health communities to enhance surveillance and epidemiologic capacity for collecting and analysing information stemming from community-based assessments of genomic variation, ${ }^{63}$ providing evidence about the burdens of various diseases. As with other fast-paced scientific and technological advancements, the intersection between genomics and public policy will continue to require both close monitoring, using methods like health technology assessment, ${ }^{7,64-68}$ as well as timely action. By this, we will have the chance to ensure the appropriate and responsible use of new genetic technologies. $^{69}$

The conglomerate of scientific and policy areas illustrates the core problem triggered by genomics. There is a need for a coherent and consistent policy framework, which is open to new innovations and flexible. Institutions like the Public Health Genomics European Network and its allied networks, associations and projects are needed to fuel an interdisciplinary discourse. Public health perceives itself as the umbrella for this discourse, but we should rather focus on health outcomes than vested rights. Both genetic 
scientists and public health practitioners should start a problem-based discourse and should not succumb to the current dogmas.

\section{Concluding remarks}

The next decade will provide a window of opportunity to prepare health professionals, public health practitioners, the public and policy makers for the advent of genomics on health and health care. This will be a doable project but will require regional, national, European and global coordination on both the vertical and horizontal levels. We argue that there is an ethical obligation to prepare society to meet this challenge and to take up the opportunities provided by the science in a medically useful, effective, efficient, socially desirable and ethically justifiable manner. Here, health literacy, health communication and empowerment in managing risks are key for opening the doors to a truly beneficial Public Health Genomics practice. This can be facilitated by implementing ethical benchmarks and legal safeguards ${ }^{70}$ such as respect for autonomy and social justice in the context of policy development.

Indeed, there is still a discussion about stigmatisation and discrimination due to genetic information not only in public but also in the scientific community. Nevertheless, whoever continues separating genomic knowledge from medical information by defining genomic knowledge as exceptional, whoever continues promoting the idea of genetic determinism and whoever continues claiming the 'genetisation', 'molecularisation' and 'medicalisation' of society has not kept up with genomic research in the past years. Explicitly, it should be emphasised at this point that public health professionals have the obligation to consider genetic information as a highly sensitive group of medical information. Still, we argue that genetic information should be seen as one cornerstone in the individual and societal health information management, just like we discuss the value of family history or different diagnostic pathways and technologies in ADPKD (autosomal-dominant polycystic kidney disease).

Furthermore, it is not the question whether the combination of public health and genomics is dangerous. ${ }^{38}$ The key question is whether more harm is done to people by omitting to integrate genomic knowledge into public health interventions, thus withholding the potential of stratified evidence-based prevention.

The public health community will lose credibility if, on the one hand, public health is promoting health literacy in a value-pluralistic and democratic society and enabling and empowering individuals for decision-making, while on the other hand, ignoring and withholding genomic knowledge, and therefore still not providing evidence-based public health interventions. In terms of the individual's 'right to know' and in terms of best practice in public health, this should be considered as a new form of discrimination.

Public health needs to prepare itself for the upcoming challenges, which derive from genomics. In this sense, it needs to strengthen the communication efforts among all sciences involved. Public health can serve as the umbrella, that spans the disciplines such as genetics, ethics, law and all other stakeholders.

\section{Acknowledgements}

This paper is an updated version of a presentation at the symposium entitled 'Fascinated with Genetics' on the occasion of the 65th birthday of Professor Leo ten Kate in Amsterdam, The Netherlands, on 17 March 2005. I (A Brand) thank Professor Leo ten Kate, pioneer of community genetics in Europe, and Professor Martina Cornel for inviting her to this outstanding symposium and for asking me to develop my thoughts on the intersection of genomics and public health. This paper is a result of the work of the Public Health Genomics European Network (PHGEN), which is funded in the Public Health Programme of the European Commission (project number 2005313).

\section{References}

1 Peltonen L, McKusick VA: Genomics and medicine: dissecting human disease in the postgenomic era. Science 2001; 291: $1224-1229$.

2 Collins FS, Patrinos A, Jordan E, Chakravarti A, Gesteland R, Walters L: New goals for the US Genome Project: 1998-2003. Science 1998; 282: 682-689.

3 Childs B, Valle D: Genetics, biology and disease. Annu Rev Genomics Hum Genet 2000; 1: 1-19.

4 Collins FS, McKusick VA: Implications of the Human Genome Project for Medical Science. JAMA 2001; 285: 540-544.

5 Burke W: Genomics as a probe for disease biology. N Engl J Med 2003; 349: 969-974.

6 Ellsworth DL, O'Donnell CJ: Emerging genomic technologies and analytic methods for population- and clinic-based research; in Khoury MJ, Little J, Burke W (eds): Human Genome Epidemiology. A Scientific Foundation for Using Genetic Information to Improve Health and Prevent Disease. Oxford, New York, Tokyo: Oxford University Press, 2004; 17-37.

7 Perleth M: Evidenzbasierte Entscheidungsunterstützung im Gesundheitswesen. Konzepte und Methoden der systematischen Bewertung medizinischer Technologien (Health Technology Assessment) in Deutschland. Berlin: Verlag für Wissenschaft und Kultur, 2003.

8 WHO (World Health Organization): Genomics and the World Health., Report of the Advisory Committee on Health Research. Geneva: WHO, 2002.

9 Thorsteinsdottier H, Daar AS, Smith RD, Singer PA: Genomics knowledge; in Smith RD, Beaglehole R, Woodward D, Drager N (eds): Global Public Goods For Health. Health Economic And Public Health Perspectives. Oxford, New York, Tokyo: Oxford University Press, 2003, pp 137-158.

10 Yoon PW: Public health impact of genetic tests at the end of the 20th century. Genet Med 2001; 3: 405-410.

11 Brand A, Brand H: Public health genetics - challenging 'public health at the crossroads'. Ital J Publ Health 2005; 3: 1-59.

12 Brand A, Dabrock P, Paul N, Schröder P: Gesundheitssicherung im Zeitalter der Genomforschung - Diskussion, Aktivitäten und Institutionalisierung von Public Health Genetics in Deutschland. Gutachten zur Bio- und Gentechnologie. Berlin: Friedrich-Ebert-Stiftung, 2004.

13 Brand A, Brand $\mathrm{H}$ : Public health genomics - relevance of genomics for individual health information management, health 
policy development and effective health services. Ital J Publ Health 2006; 4: 24-34.

14 Zimmern R: Genetics; in Griffiths S, Hunter DJ (eds): Perspectives in Public Health. Oxford: Radcliffe Medical Press, 1999, pp $131-140$.

15 Holtzman NA, Marteau TM: Will genetics revolutionize medicine? 2000; 343: 141-144.

16 Khoury MJ, Burke W, Thomson E: Genetics in public health: a framework for the ingegration of human genetics into public health practice; in Khoury MJ, Burke W, Thomson EJ (eds): Genetics and Public Health in the 21st Century. Using Genetic Information to Improve Health and Prevent Disease. Oxford, New York, Tokyo: Oxford University Press, 2000, pp 3-23.

17 Zimmern R, Cook C: Genetics and Health. Policy Issues for Genetic Science and their Implications for Health and Health Services. The Nuffield Trust Genetics Scenario Project. London: The Nuffield Trust, 2000.

18 Omenn GS: Public health genetics: an emerging interdisciplinary field for the post-genomic era. Annu Rev Public Health 2000; 21: $1-13$.

19 Walt G: Health Policy: An Introduction to Process and Power. London, New Jersey: Zed Books, 1994.

20 Khoury MJ: Relationship between medical genetics and public health: changing the paradigm of disease prevention and the definition of a genetic disease. Am J Med Gen 1997; 17: 289-291.

21 Baird PA: Identification of genetic susceptibility to common diseases: the case for regulation. Perspect Biol Med 2000; 45: $516-528$

22 Lai E, Bansal A, Hughes A: Medical applications of haplotypebased SNP maps: learning to walk before we run. Nat Gen 2002; 32: 353.

23 Gibbs RA, Belmont JW, Hardenbol P: The International HapMap Project. Nature 2003; 426: 789-796.

24 Guttmacher AE, Collins FS: Genomic medicine - a primer. 2002; 347: 1512-1521.

25 Antonovsky A: Unraveling the Mystery of Health. How People Manage Stress and Stay Well. San Francisco: Jossey Bass, 1987.

26 Sing CF, Stengard JH, Kardia SL: Genes, environment, and cardiovascular disease. Art Thromb Vasc Biol 2003; 23: 1950.

27 Dorman JS, Mattison DR: Epidemiology, molecular biology and public health; in Khoury MJ, Burke W, Thomson EJ (eds): Genetics and Public Health in the 21st Century. Using Genetic Information to Improve Health and Prevent Disease. Oxford, New York, Tokyo: Oxford University Press, 2000, pp 103-121.

28 Little J: Reporting and review of the human genome epidemiology studies; in Khoury MJ, Little J, Burke W (eds): Human Genome Epidemiology. A Scientific Foundation for Using Genetic Information to Improve Health and Prevent Disease. Oxford, New York, Tokyo: Oxford University Press, 2004, pp 168-192.

29 The Wellcome Trust Case Control Consortium: Genome-wide association study of 14000 cases of seven common diseases and 3000 shared controls. Nature 2007; 447: 661-678.

30 Hoffmann K, Mattheisen M, Dahm S et al: A German genomewide linkage scan for typ 2 diabetes supports the existence of a metabolic syndrome locus on the chromosome $1 \mathrm{p} 36.13$ and a type 2 diabetes locus on chromosome 16p12.2. Diabetologia 2007; 50: $1418-1422$.

31 Cooke GS, Hill AVS: Genetics of susceptibility to human infectious diseases. Nat Rev Genet 2001; 2: 967-977.

32 Khoury MJ: From genes to public health: the applications of genetic technology in disease prevention. Am J Public Health 1996; 86: 1717-1722.

33 Brand A: Prädiktive Gentests - Paradigmenwechsel für Prävention und Gesundheitsversorgung? Gesundheitswesen 2002; 64: 224-229.

34 French ME, Moore JB: Harnessing Genetics to Prevent Disease and Promote Health. Partnership for Prevention. Washington, 2003.

35 Schulte in den Bäumen T: Governance in genomics: a conceptual challenge for public health genomics law. Ital J Publ Health 2006; 3: $46-52$.
36 Michigan Center for Genomics and Public Health: Ethical, Legal and Social Issues in Public Health Genetics (PHELSI) 2004, http://www.sph.umich.edu/genomics/media/subpage_autogen/ PHELSI.pdf.

37 Beskow LM, Khoury MJ, Baker TG, Thrasher JF: The integration of genomics into public health research, policy and practice in the United States. Community Genet 2001; 4: 2-11.

38 Brand A: Public health and genetics - dangerous combination? View-point section. Eur J Publ Health 2005; 15: 114-116.

39 Murray T: Genetic exceptionalism and, future diaries': is genetic information different from other medical information?; in Rothstein M (ed):: Genetic Secrets: Protecting Privacy and Confidentiality in the Genetic Era. New Haven: Yale University Press, 1997, pp 60-73.

40 Khoury MJ, Little J, Burke W: Human genome epidemiology: scope and strategies; in Khoury MJ, Little J, Burke W (eds): Human Genome Epidemiology. A Scientific Foundation for Using Genetic Information to Improve Health and Prevent Disease. Oxford, New York, Tokyo: Oxford University Press, 2004, pp 3-16.

41 Manolio TA, Bailey-Wilson JE, Collins FS: Genes, environment and the value of prospective cohort studies. Nat Rev Genet 2006; 7: $812-820$.

42 Wichmann H-E, Gieger C, Ilig T: KORA-gen - resource for population genetics, controls and a broad spectrum of disease phenotypes. Gesundheitswesen 2005; 67: 26-30, special edition 1 .

43 Peyser PA, Burns TL: Approaches to quantify the genetic component of and identify genes for complex traits; in Khoury MJ, Little J, Burke W (eds): Human Genome Epidemiology. A Scientific Foundation for Using Genetic Information to Improve Health and Prevent Disease. Oxford, New York, Tokyo: Oxford University Press, 2004, pp 38-57.

44 Frankish CJ, Kwan B, Ratner PA, Higgins JW, Larsen C: Challenges of citizen participation in regional health authorities. Soc Sci Med 2002; 54: 1471-1480.

45 O'Neill O: Autonomy and Trust in Bioethics. Cambridge: Cambridge University Press, 2002.

46 Geier M, Schröder P: The concept of human dignity in biomedical law; in Sándor J, den Exter AP (eds): Frontiers of European Health Law: A Multidisciplinary Approach. Delft: Erasmus University Press-DocVision, 2003, pp 146-182.

47 Tauber AI: Sick autonomy. Perspect Biol Med 2003; 46: 484-495.

48 UNESCO: International Declaration on Human Genetic Data. Paris: UNESCO, 2003.

49 Burke W, Atkins D, Gwinn M: Genetic test evaluation. Information needs of clinicians, policy makers and the public. Am J Epidemiol 2002; 156: 311-318.

50 Wilson JMG, Jungner G: Principles and Practice of Screening for Disease. Public health papers 34. Geneva: World Health Organization (WHO), 1968.

51 Burke W, Coughlin SS, Lee NC, Weed DL, Khoury MJ: Application of population screening principles to genetic screening for adultonset conditions. Genet Test 2001; 5: 201-211.

52 Khoury MJ, McCabe LL, McCabe ERB: Population screening in the age of genomic medicine. 2003; 348: 50-58.

53 European Commission: 25 Recommendations on the Ethical, Legal and Social Implications of Genetic Testing. Brussels: European Commission, 2004.

54 Dabrock P: Capability-Approach und Decent Minimum. Befähigungsgerechtigkeit als Kriterium möglicher Priorisierung im Gesundheitswesen. Zeitschrift für Evangelische Ethik 2001; 46: $202-215$.

55 Wilkinson RG: Unhealthy Societies. The Afflictions of Inequality. London: Routledge, 1996.

56 ten Kate LP: Editorial. Community Genet 1998; 1: 1-2.

57 ten Kate LP: Community genetics in The Netherlands; in Khoury MJ, Burke W, Thomson EJ (eds): Genetics and Public Health in the 21st Century. Using Genetic Information to Improve Health and Prevent Disease. Oxford, New York, Tokyo: Oxford University Press, 2000, pp 291-299. 
58 Donaldson RJ, Donaldson LJ: Essential Public Health Medicine. Plymouth: Petroc Press, 1998.

59 IoM (Institute of Medicine): The Future of Public Health. Division of Health Care Services. Committee for the Study of the Future of Public Health. Washington, DC: National Academy Press, 1988, pp 7-8.

60 Rose G: The Strategy of Preventive Medicine. Oxford, New York, Tokyo: Oxford University Press, 1992.

61 Schröder P: Gendiagnostische Gerechtigkeit. Eine ethische Studie über die Herausforderungen postnataler genetischer Prädiktion. Münster Hamburg London: LIT Verlag, 2004.

62 Sass HM: A 'contract model' for genetic research and health care for individuals and families. Eubios J Asian Int Bioethics 2001; 11: $130-132$.

63 Annas GJ: Rules for research on human genetic variation - lessons from Iceland. 2000; 342: 1830-1833.

64 Banta HD, Luce BR: Health Care Technology and its Assessment. An International Perspective. New York, Tokyo: Oxford University Press, 1993.

65 Pollitt RJ, Green A, McCabe CJ et al: Neonatal Screening for Inborn Errors of Metabolism: Cost, Yield and Outcome. Boldrewood: The
National Coordinating Centre for Health Technology Assessment (NCCHTA), 1997.

66 Brand A: Health technology assessment als Basis einer Prioritätensetzung; in Fozouni B, Güntert B (eds): Prioritätensetzung im deutschen Gesundheitswesen. Berlin: Logos Verlag, 2002b, pp 158-163.

67 Moldrup C: Medical technology assessment of the ethical, social, and legal implications of pharmacogenomics. A research Proposal for an Internet Citizen Jury. Int J Technol Assess Health Care 2002; 18: $728-732$.

68 AETMIS (Agence d'evaluation des technologies et des modes d'intervention en sante): Health Technology Assessment in Genetics and Policy-making in Canada: Towards a sustainable development. Report from a symposium held September 11th and 12th, 2003 in Montral. Montreal: AETMIS, 2003.

69 Shani S, Siebzehner MI, Luxenburg O, Shemer J: Setting priorities for the adoption of health technologies on a national level - the Israeli experience. Health Policy 2000; 54: 169-185.

70 Antonopoulou L, van Meurs P: The precautionary principle within European Union public health policy. The implementation of the principle under conditions of supranationality and citizenship. Health Policy 2003; 66: 179-197. 